\title{
Exercise stress test in the pediatric population - single center experience
}

\section{○Zijo Begić', (ONedim Begići'*, OEdin Begić ${ }^{2}$}

'Clinical Center University of Sarajevo, Sarajevo, Bosnia and Herzegovina

${ }^{2}$ General Hospital "Prim.dr. Abdulah Nakaš", Sarajevo, Bosnia and Herzegovina
RECEIVED:

December 12, 2020

ACCEPTED:

December 18, 2020

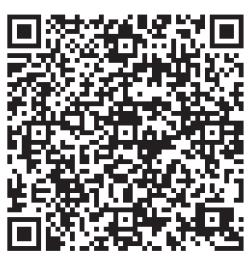

$\square$ Cardiologia Croatica 2021;16(1-2):44.
KEYWORDS: exercise stress tests, pediatrics, heart defects.

CITATION: Cardiol Croat. 2021;16(1-2):44. | https://doi.org/10.15836/ccar2021.44

*ADDRESS FOR CORRESPONDENCE: Zijo Begić, Pediatric Clinic, Clinical Center University of Sarajevo, Patriotske lige 81, 71000 Sarajevo, Bosnia and Herzegovina. / Phone: +38761338096 / E-mail: begiczijo@gmail.com

ORCID:Zijo Begić, https://orcid.org/0000-0002-1863-5755 • Nedim Begić, https://orcid.org/0000-0001-5964-2305 Edin Begić, https://orcid.org/0000-0001-6842-262X

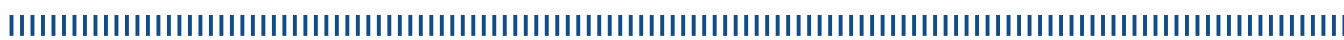

Introduction: Exercise stress test (ergometry) in pediatric cardiology practice is used to examine the condition and functional ability of the heart in children. It is performed using a bicycle ergometer or treadmill, estimating and measuring the amount of physical activity, heart rate, blood pressure values and electrocardiogram. ${ }^{1,2}$ The aim of article was to present the role and importance of exercise stress test in everyday clinical pediatric cardiac practice.

Patients and Methods: Based on data from medical histories and the Register of Exercise stress test from the Pediatric Clinic, Clinical Center of the University of Sarajevo in the period from April 2008 to January 2020, we conducted a retrospective and descriptive study.

Results: During mentioned period, 840 exercise stress tests were performed on a treadmill according to the Naughton protocol. There were 474 boys (56.4\%) and 366 girls (43.6\%). According to age, 375 (44.6\%) patients were aged 15-19, and 465 (55.3\%) aged 5-15. Indications for the test were congenital heart defects (CHD), before and after surgery in 321 (38.2\%) cases, significant or insignificant arrhythmias (incisiona) in 269 (32\%) patients, assessment of the possibility of playing sports and performing physical activity in $86(10.2 \%)$ patients, chest pain in 64 (7.6\%) patients, arterial hypertension in 51 (6.1\%) patients, transient loss of consciousness in 36 (4.3\%) patients, while other indication were in $13(1.6 \%)$ patients. Positive test was in 126 patients (15\%), while control ergometry was indicated in 49 patients (6\%).

Conclusion: Exercise stress test has a significant place in examining the causes of pain in children with CHD before or after surgery, detection and treatment of arrhythmias, as well as assessment of physical activity and ability of doing sport for the child.
LITERATURE IIIIIIIIIIIIIIIIIIIIIIIIIIIIIIIIIIIIIIIIIIIIIIIIIIIIIIIIIIIIIIIIIIIIIIIIIIIIIIIIIIIIIIIIIIIIIIII

1. Kyle WB, Macicek SL, Lindle KA, Kim JJ, Cannon BC. Limited utility of exercise stress tests in the evaluation of children with chest pain. Congenit Heart Dis. 2012 Sep-0ct; $7(5): 455-9$. https://doi.org/10.1111/j.1747-0803.2012.00702.x

2. Miliaresis C, Beker S, Gewitz M. Cardiopulmonary stress testing in children and adults with congenital heart disease. Cardiol Rev. 2014 NovDec;22(6):275-8. https://doi.org/10.1097/CRD.0000000000000039 